\title{
Spatial and Temporal Analysis of Drought in Nepal using Standardized Precipitation Index and its Relationship with Climate Indices
}

\author{
M. Sigdel ${ }^{1}$ \& M. Ikeda ${ }^{1}$ \\ ${ }^{1}$ Graduate School of Environmental Science, Hokkaido University, N10 W 5, Sapporo Graduate School \\ Hokkaido 060-0810, Japan \\ E-mail:sigdelbro@gmail.com
}

\begin{abstract}
Drought over Nepal is studied on the basis of precipitation as a key parameter. Using monthly mean precipitation data for a period of 33 years, Standardized Precipitation Index (SPI) is produced for the drought analysis with the time scale of 3 months (SPI-3) and 12 months (SPI-12) as they are applicable for agriculture and hydrological aspects, respectively. Time-space variability is explored based on Principal Component Analysis (PCA) along with Rotated PCA (RPCA). Four rotated components were explored for both SPI-3 and SPI-12 representing climatic variability with cores over eastern, central and western Nepal separately. Droughts associated with SPI-3 occurred almost evenly over these regions. Droughts associated with SPI-12 were consistent with SPI-3 for summer, since summer precipitation dominates annual precipitation. Connection between SPI and the climate indices such as Southern Oscillation Index (SOI) and Indian Ocean Dipole Mode Index (DMI) was studied, suggesting that one of the causes for summer droughts is El Nino, while the winter droughts could be related with positive DMI.
\end{abstract}

Keywords: Standardized Precipitation Index, Nepal, Principal component analysis, Drought

\section{INTRODUCTION}

Approximately $85 \%$ of natural disasters are related to extreme meteorological events (Obasi, 1994). Drought is one of the most complicated and least understood natural hazards, affecting more people than any other hazards (Wilhite, 2000). It is a slowly developing phenomenon, only indirectly affecting our life. Although drought first appears as below-average rainfall within a normal part of climate, it can develop as an extreme climatic event and turn into a hazardous phenomenon which can have a severe impact on communities and water dependent sectors (McKee et al., 1993).
Precipitation is the primary factor controlling the formation and persistence of drought conditions. Other climatic factors such as high temperature, high wind, and low relative humidity are often associated with it in many regions of the world and can significantly aggravate its severity. In recent years, due to the effect of climate change drought studies are getting special attention (Byun and Wilhite, 1999). Along with this increased vulnerability, concern exists because some research suggests that drought in the future may be amplified in certain areas due to changes in climate variability and extremes resulting from global warming (www.ncdc.noaa.gov). 
Although there have been some studies on precipitation patterns over Nepal (e.g. Shrestha, 2000; Shrestha et al., 2000), the study concerning on drought is very limited and new. Summer monsoon, June to September (JJAS) is associated with around 80 percent of total precipitation while winter season's western disturbance has relatively weak effects on precipitation which lies from December to February. Since winter is basically dry, a small amount of reduction in rain fall may have a serious impact on certain activities such as crop production. Dependency on precipitation for agricultural practices may lead serious consequences on the national economy due to longterm drought situation. Careful monitoring as well as early warning for dryness is a big challenge for drought management in Nepal. From the historical observations, this country has noticed that the serious droughts gave enormous nationwide impacts.

Standardized Precipitation Index (SPI) was developed by McKee et al. (1993) as an alternative to the Palmer Index in Colorado (Heim, 2002). Although SPI is a comparatively new index, it has been used in Turkey, Argentina, Canada, Spain, Korea, Hungary, China and India for real time monitoring or retrospective analyses of droughts (Patel et al., 2007). Once we search a cause of a drought event, a coupled atmosphere-ocean system may provide a climatic index as control mechanism of precipitation. El Nino-Southern Oscillation (ENSO) phenomenon over the tropical Pacific is quite important because of its huge impacts on hydro-meteorological disasters like floods and droughts beyond the tropical region. According to Saji and Yamagata (2003) Indian Ocean Dipole mode index (DMI) is a recently noticed player for precipitation variability along peninsular and western Indian subcontinent.
Therefore, hydroclimatic variability around Nepal can not be distant from the influence of these indices like ENSO and DMI.

The present study aims at focusing on the drought index (SPI) over the country, Nepal, and focuses on the analysis of spatial pattern and temporal progression of the drought events. Linkage is sought between the drought and the climate indices of the tropical Pacific and Indian Ocean.

\section{DATA AND METHODS}

Nepal lies between $80^{\circ} 04^{\prime}$ and $88^{\circ} 12^{\prime}$ east longitudes and $26^{\circ} 12^{\prime}$ and $30^{\circ} 27^{\prime}$ north latitudes of South Asian region. The topography of Nepal varies from plain low land in south to higher Himalaya range towards north. Climatic regimes vary from subtropical in southern plains to glacial in northern Mountains. Altogether 26 unevenly distributed precipitation stations (Figure 1) were used for this study representing different geographical areas like mountains, hills and plain land. The monthly mean precipitation station data from January 1971 to December 2003 were used, which were provided by Department of Hydrology and Meteorology, Government of Nepal. As alternative sources, we checked the gridded observation data of CMAP, GPCP and GPCC although these datasets give much lower magnitude of precipitation than the rain gauge station data. In addition, monthly climatic indices such as SOI and sea surface temperature (SST) of Nino 3 region of the respective period were taken from Climate prediction center, NOAA, available on http://www.cpc.noaa.gov/ data/indices. Also Indian Ocean Dipole mode Index (DMI) was used to compare among SPI and other indices. 


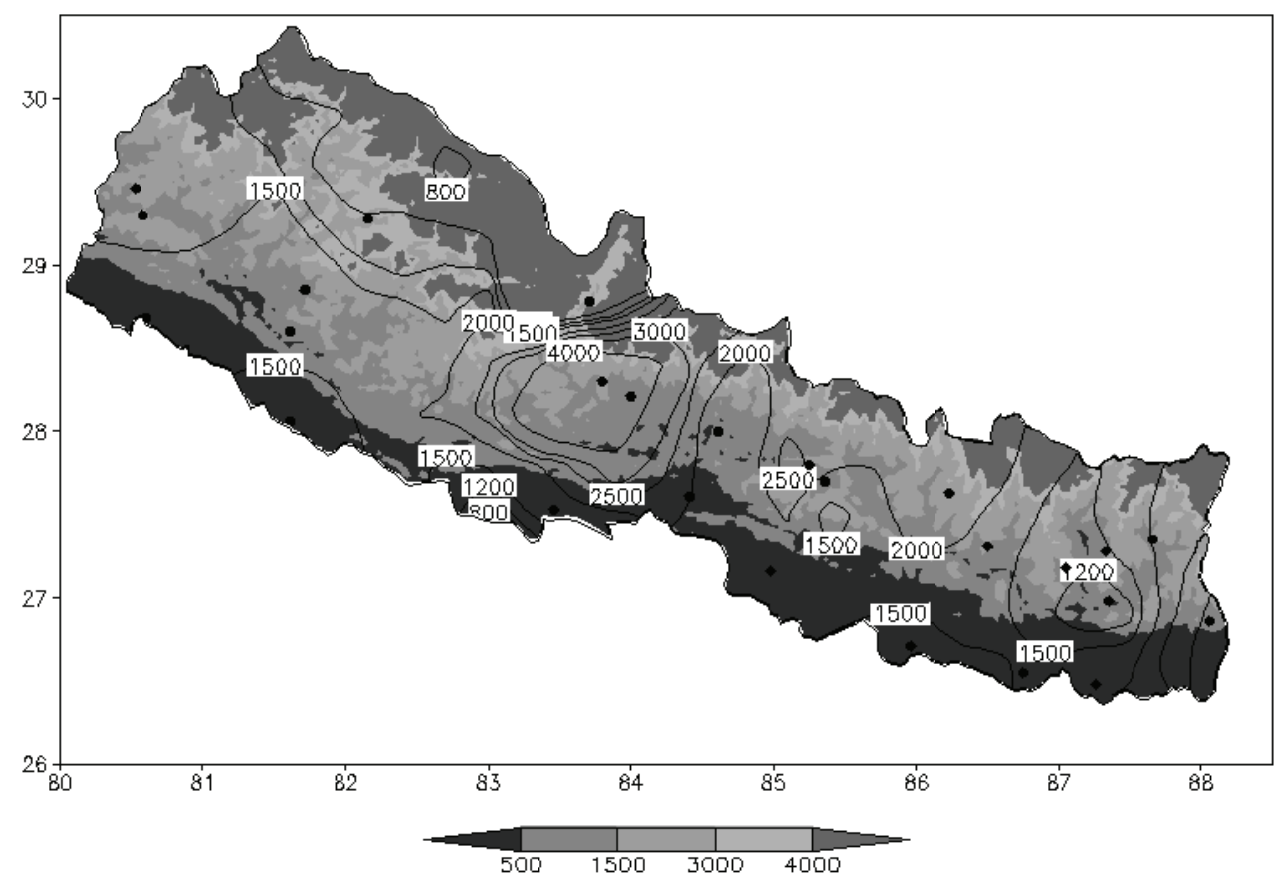

Figure 1: Precipitation stations over Nepal (by dots) used for the study and mean annual precipitation over Nepal (contour in $\mathrm{mm}$ ), and elevation in color contour (in meter).

\subsection{SPI AND PRINCIPAL COMPONENT ANALYSIS}

SPI is simply the result of the normal quantile transformation applied to a fitted parametric distribution of the original value. The main advantage of SPI exists in a quantitative analysis of shortage of precipitation with reference to a climatic mean state: e.g.: annual precipitation itself is dominated by summer precipitation, whereas small precipitation variability in the other seasons may be crucial to drought but plays negligible contribution to annual one. Another advantage is that SPI with different time scales (McKee et al., 1993; Komuscu, 1999) can identify various drought types. The SPI is comparable in both time and space, but it is not affected by geographical and topographical differences (Lana et al., 2001). This versatility allows the SPI to monitor short term water supplies, such as soil moisture, important for agricultural production and longer term water resources such as ground water supplies, stream flow and lake reservoir levels (Hayes et al., 1999). In this study we applied the drought classification category based on Mckee et al. (1993) as shown in Table 1.

Table 1: Classification of drought categories based on McKee et al. (1993)

\begin{tabular}{|l|l|}
\hline \multicolumn{1}{|c|}{ SPI } & \multicolumn{1}{c|}{ Category } \\
\hline Less than -1.0 & Moderate drought \\
\hline Less than -1.5 & Severe drought \\
\hline Less than -2.0 & Extreme drought \\
\hline
\end{tabular}

The SPI is computed by fitting a probability density function to a given precipitation summed over the time scale of interest. The monthly precipitation is fitted to gamma distribution. The probability density function of Gamma distribution is defined

as $\mathrm{g}(\mathrm{x}) \frac{1}{\beta^{\alpha} \Gamma(\alpha)} x^{\alpha-1} e^{-x / \beta}=$ for $\mathrm{x}>0$ 
where, $x>0, \alpha$ is a shape parameter. $\beta>0, \beta$ is scale parameter

$\mathrm{x}>0$, $\mathrm{x}$ is the precipitation amount

$$
\Gamma(a)=\int_{0}^{\infty} y^{\alpha-1} e^{-y} d y \Gamma(\mathrm{a}) \text { is the gamma function. }
$$

Fitting the distribution to the data requires alpha and beta to be estimated. The maximum likelihood function is given as follows:

$$
\hat{\alpha}=\frac{1}{4 A}\left(1+\sqrt{1+\frac{4 A}{3}}\right)
$$

$\hat{\beta}=\frac{\bar{x}}{\hat{\alpha}}$, where $A=\ln (\bar{x})-\frac{\sum \ln (x)}{n}$

$\mathrm{n}=$ number of precipitation observations

The resulting parameters are then used to find the cumulative probability of an observed precipitation event for the given month and time scale for the station in concern. The cumulative probability is given by:

$$
G(x)=\int_{0}^{x} g(x) d x=\frac{1}{\beta \alpha \Gamma(\hat{\alpha})} \int_{0}^{x} x^{\hat{\alpha-1}} e^{-x / \hat{\beta}} d x
$$

letting $t=x / \hat{\beta}$ equation becomes

$$
G(x)=\frac{1}{\Gamma(\hat{\alpha})} \int_{0}^{x} t^{\hat{\alpha-1}} e^{-t} d t
$$

since gamma function is undefined for $\mathrm{x}=0$ and precipitation distribution may contain zero, cumulative probability becomes:

$H(x)=q+(1-q) G(x)$ where $q$ is the probability of zero. $\mathrm{H}(\mathrm{x})$ is then transformed to a normal distribution with a zero mean and unit variance. The above approach is simple but not practical for computing SPI for large numbers of data points. As used by Edwards and McKee (1997), the approximate conversion provided by Abramowitz and Stegun (1965) is alternative and was used in this study;

$$
\begin{aligned}
& Z=S P I=-\left(t-\frac{\mathcal{C}_{0}+c_{1} t+c_{2} t^{2}}{1+d_{1} t+d_{2} t^{2}+d_{3} t^{3}}\right) \quad \text { for } 0<\mathrm{H}(\mathrm{x})<0.5 \\
& Z=S P I=+\left(t-\frac{\mathcal{C}_{0}{ }^{+}{\mathcal{C}_{1}}^{t+} \mathcal{C}_{2} t^{2}}{1+d_{1}{ }^{t+} d_{2} t^{2}+d_{3} t^{3}}\right) \quad \text { for } 0.5<\mathrm{H}(\mathrm{x})<1.0
\end{aligned}
$$

where, $t=\sqrt{\ln \left(\frac{1}{(H(x))^{2}}\right)}$ for $0<\mathrm{H}(\mathrm{x})<0.5$

$t=\sqrt{\ln \left(\frac{1}{(1.0-H(x))^{2}}\right)}$ for $0.5<\mathrm{H}(\mathrm{x})<1.0$

$\mathrm{c}_{0}=2.515517, \quad \mathrm{c}_{1}=0.802853, \quad \mathrm{c}_{2}=0.010328$, $\mathrm{d}_{1}=1.432788, \mathrm{~d}_{2}=0.189269, \mathrm{~d}_{3}=0.001308$

PCA is an extremely useful linear tool for data compression, orthogonalization, and filtering. PCA attempts to synthesize in a small number of new uncorrelated variables most of the total variation of a large number of highly intercorrelated variables. This reduction in dimensionality can lead to a more tractable understanding and interpretation of the data. The new uncorrelated variables are called principal components (PCs) and consist of linear combinations of the original variables. The coefficients of the linear combinations are called loadings and they represent the weight of the original variables in the PCs.

Dominant space-time variation of SPI was analyzed for 3-month time scale (SPI-3) and 12-month time scale (SPI-12) using the principal component analysis (PCA). This method consists of computing eigenvalues and eigenvectors of covariance matrix, where eigenvectors properly normalized are the loadings, while each eigenvalue explains fraction of total variance explained by each loading (Bonaccorso et.al., 2003). According to Bordi et al. (2004) spatial patterns describe the correlation between SPI series at single stations and the corresponding 
principal component (PC) time series, while the corresponding temporal series provides the time behavior for the PC with a focus on the region identified.

\section{SPATIAL AND TEMPORAL ANALYSIS OF SPI}

The annual distribution of precipitation over the country is shown in Figure 1. The amount of annual precipitation generally decreases from east to west. However, there are certain pockets with heavy annual rainfall totals, e.g., in central Nepal. For all the studied stations we calculated the SPI and obtained the SPI series for Nepal with the two temporal scales SPI-3 and SPI-12. Then this data series was analyzed through PCA. We utilized unrotated PCA as a basic analysis for the possible linkage with large-scale atmospheric circulations and used rotated PCA (RPCA) as an extended analysis to identify drought characteristics in the sub-regions.

One of the criteria for RPCA is the percentage of variance accounted and recommends achieving high percentage in application of this procedure to rotate the loadings (Bordi and Sutera, 2002; Bonaccoros et al., 2003). We applied varimax rotation for the first eight components of SPI-12 and first nine components of SPI-3, both of which explain around 78 percentage of total variances. From the statistical point of view, the higher modes may not provide robust results. Hence, we examined rotation of the first two PCs also. As we expected it, the area representation was not localized but showed eastern and western modes only. Therefore, from the objective of localizing the SPI distributions, we used the high percentage method in this paper. The results of the first four rotated components whose spatial patterns show higher loadings in certain regions are discussed.

\section{A. SPATIO-TEMPORAL PATTERN FOR SPI -3 AND SPI-12}

About 38.5 percent of variance is explained by the first unrotated component (PC1). The spatial loadings are almost positive having higher values in eastern and central Nepal and hence higher correlation between its time series and SPI at the stations in these regions (Figure 2a). Thus, the fluctuating time series of these particular regions give the dry and wet conditions as shown in Figure 2 b; e.g., drought occurs with positive spatial loadings and negative time series. We considered the representative region based on loadings larger than 0.5 i.e., contours in the spatial map. The PC2 explains 12.8 percent of variance representing contrast between eastern and western regions (not shown). The difference between PC1 and PC2 may be caused by difference in seasonal precipitation regime, since the eastern and central regions receive precipitation in summer (Shrestha, 2000) and more rain falls over the western region in winter. PC1 may be related with large-scale circulation such as ENSO, while PC2 can be caused by wintertime circulation extending to the Arabian Sea.

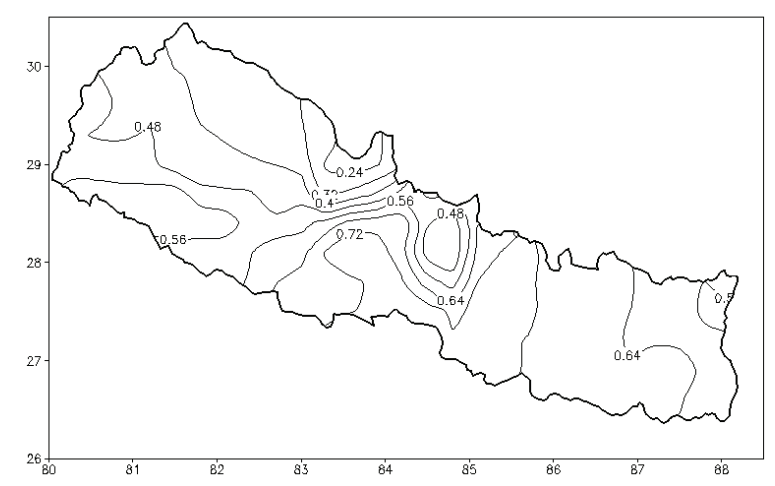

Figure 2: (a) Spatial patterns of PC1 of unrotated SPI-3 


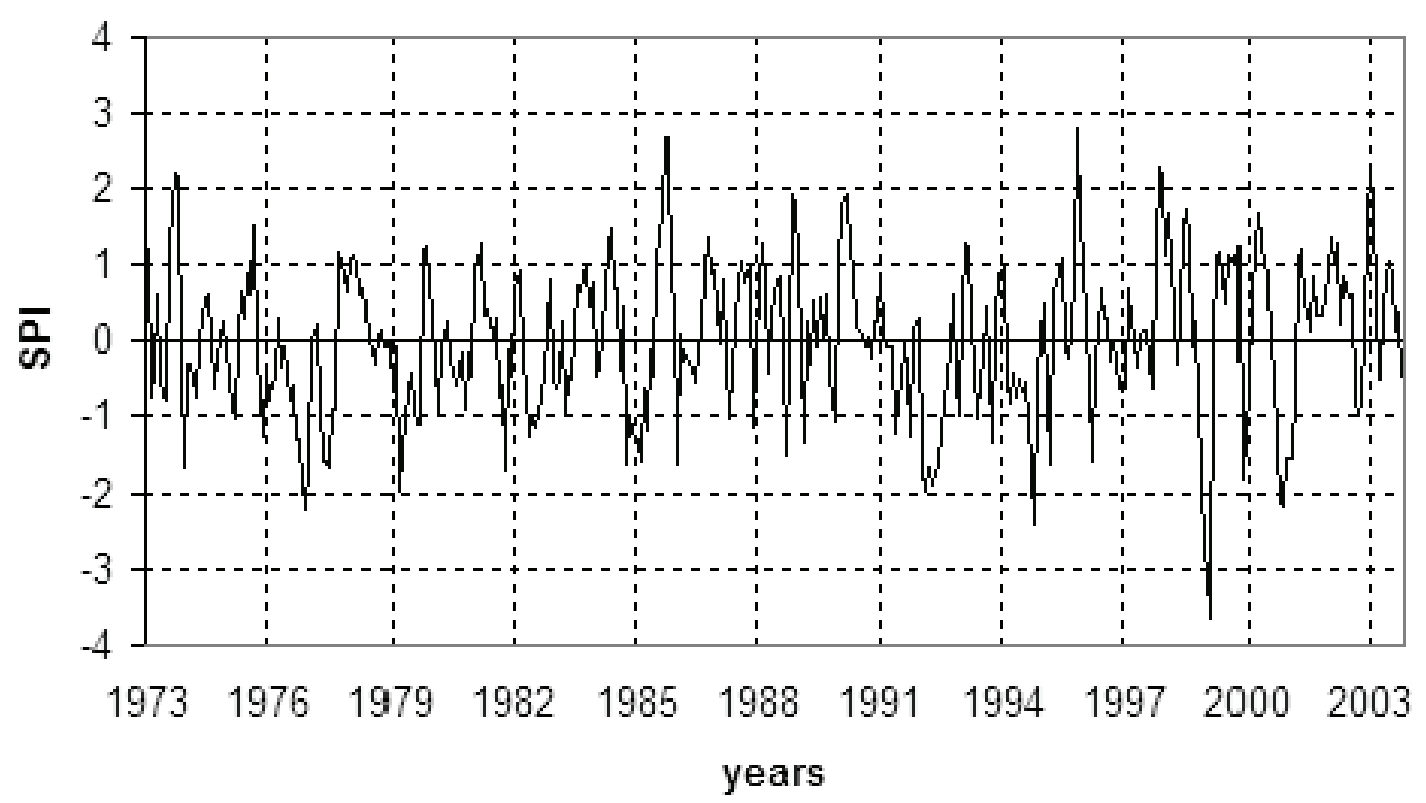

Figure 2: (b) Temporal patterns of PC1 of unrotated SPI-3

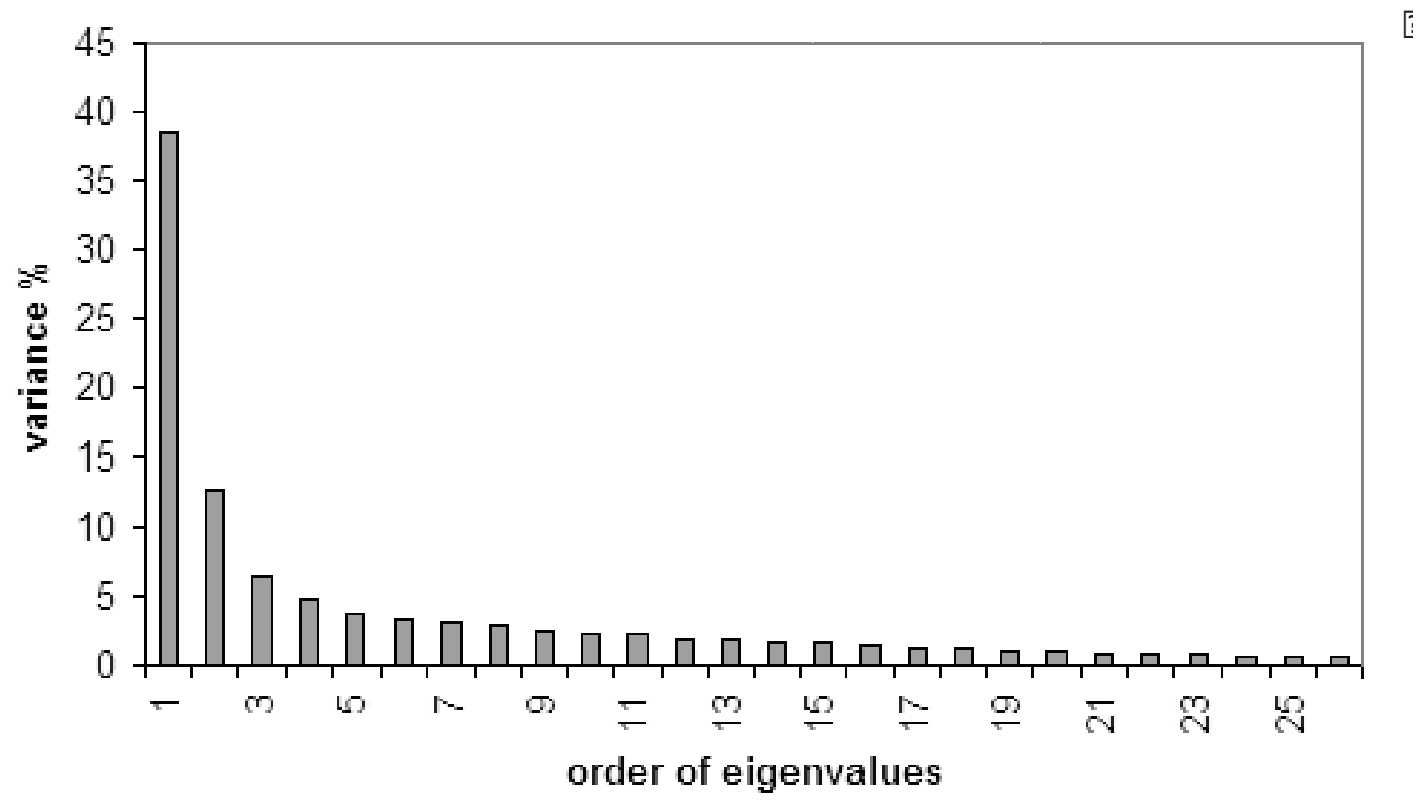

Figure 2: (c) Percentage of variance against its eigenvalues of SPI-3 
The first component (RPC1) of rotated principal component analysis (RPCA) represents eastern Nepal with maximum loading up to 0.7 explaining 14.2 percent of variance (Figure3a). The temporal pattern associated with RPC1 is shown in Figure 4a. Several dry episodes were detected having larger negative values, yielding critical situations for years 1981-82, 1986, 1992, 1994, 1997, 1999 and 2001. The RPC2 explains 13 percent of variance, as higher values of loadings are observed in the southeastern region (Figure 3b).

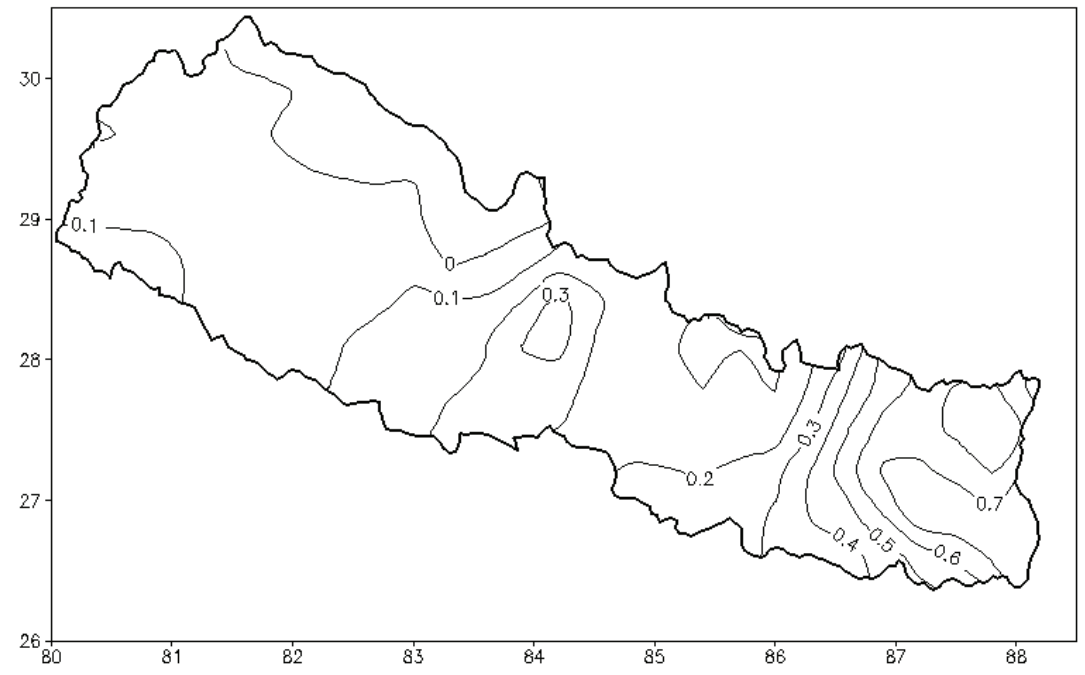

Figure 3: (a) Spatial patterns of rotated first principal component (RPC1) of SPI-3

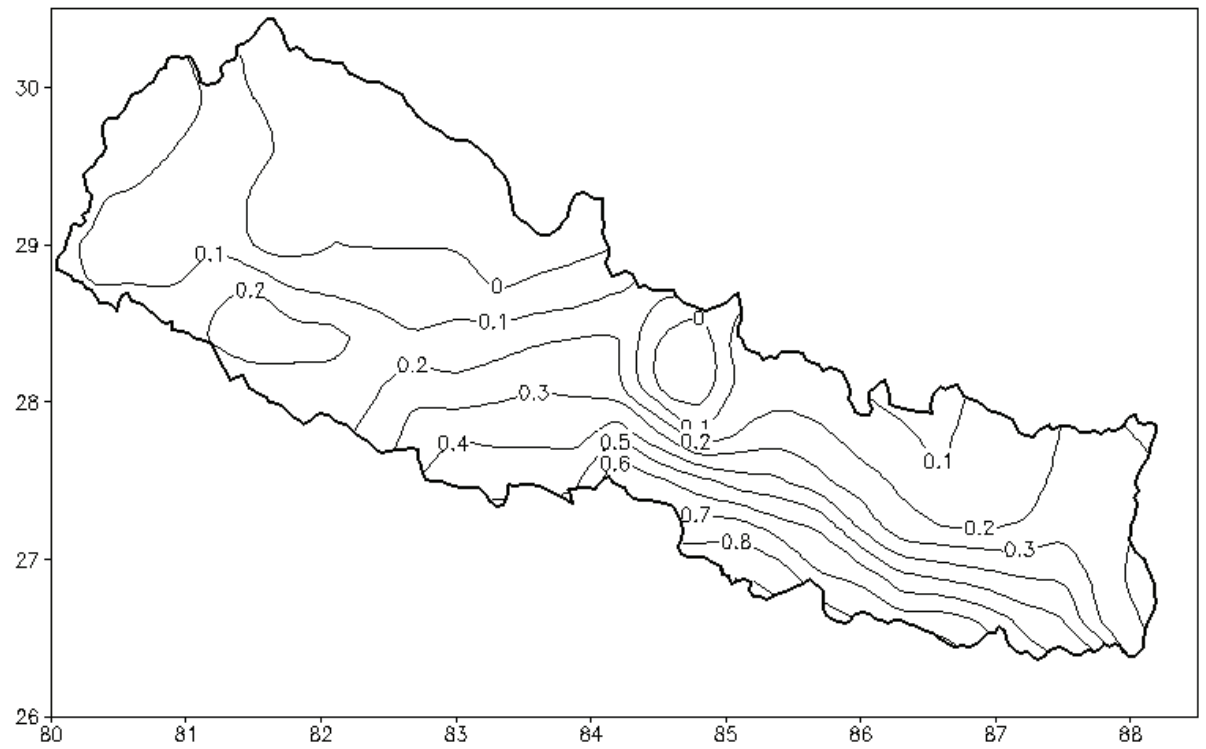

Figure 3: (b) Spatial patterns of rotated second principal component (RPC2) of SPI-3 


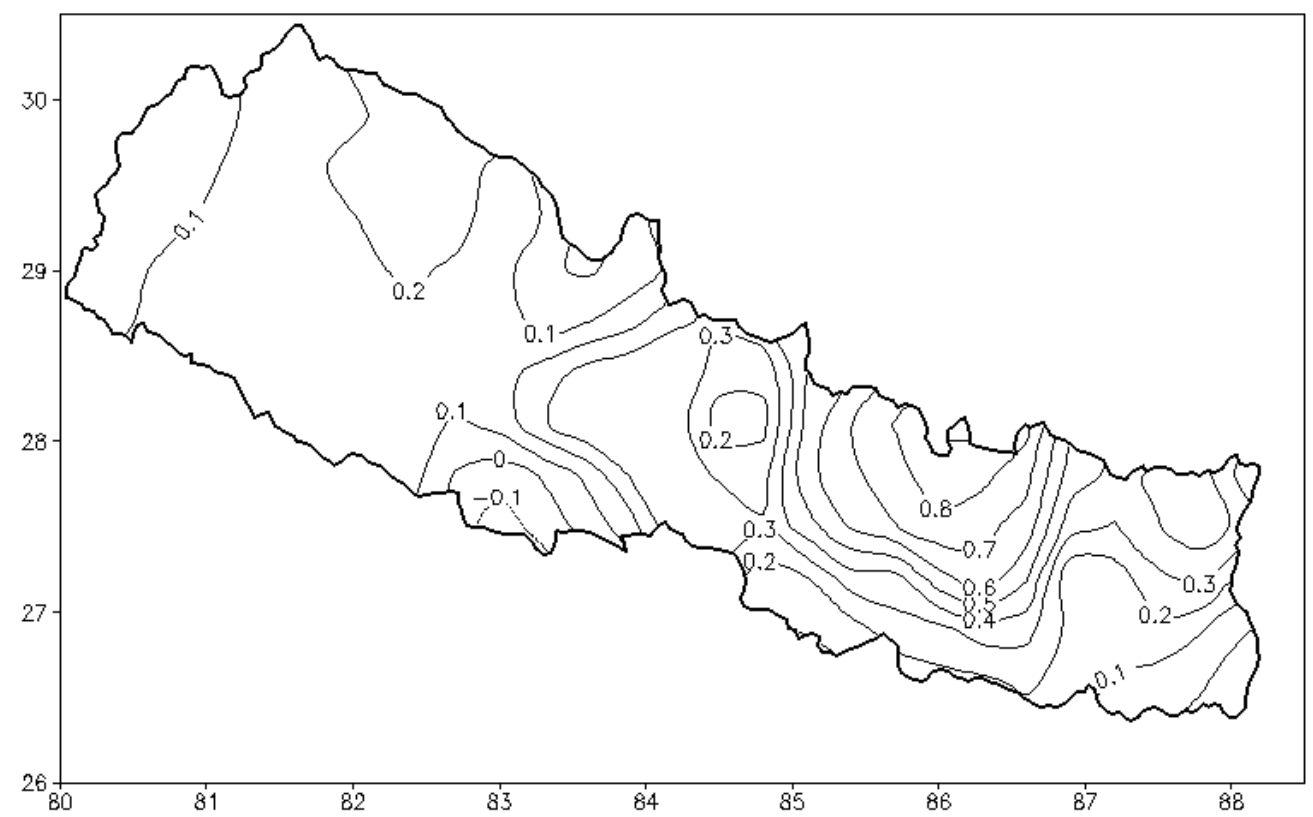

Figure 3: (c) Spatial patterns of rotated third principal component (RPC3) of SPI-3

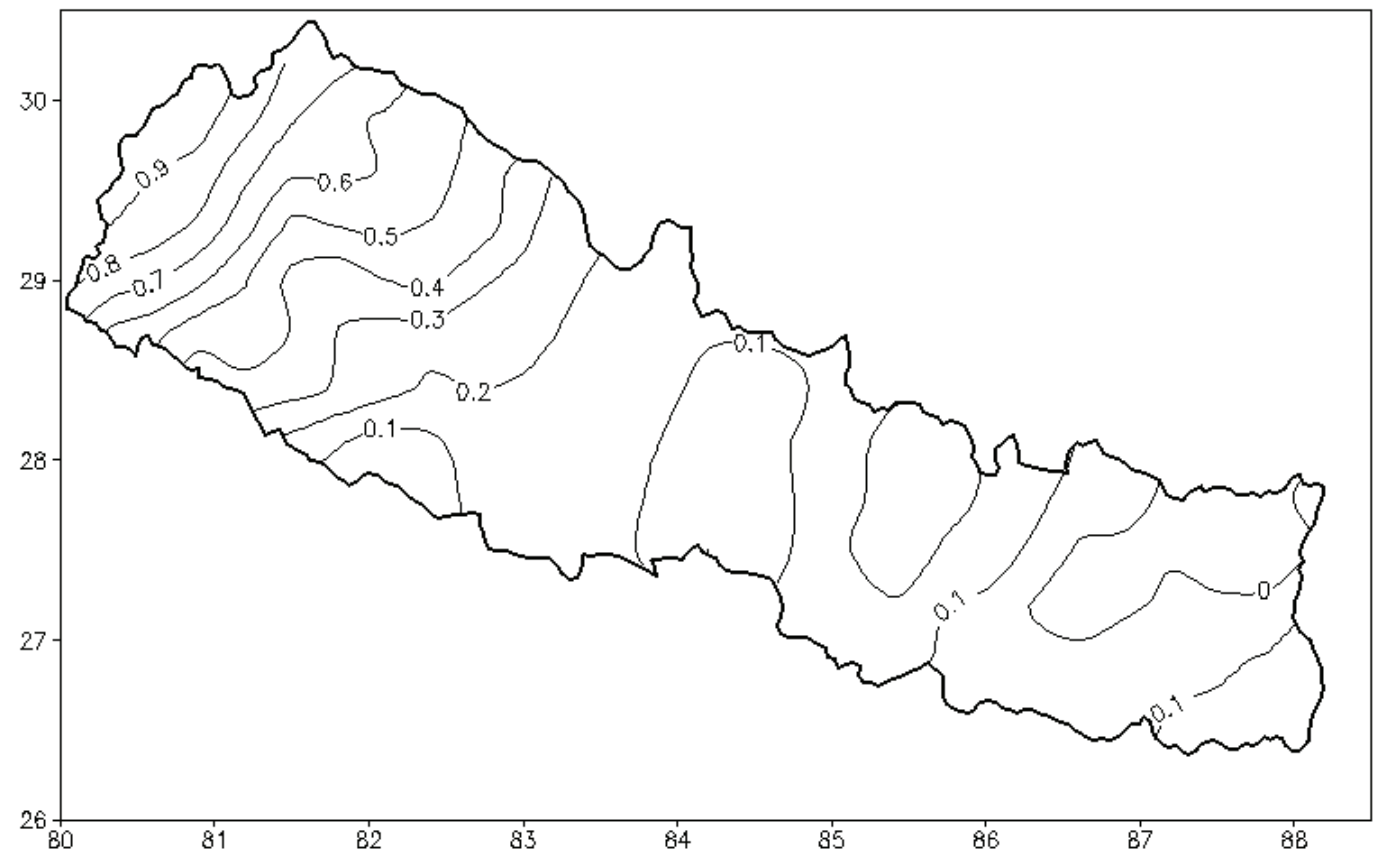

Figure 3: (d) Spatial patterns of rotated fourth principal component (RPC4) of SPI-3 
Similarly, RPC3 (10.6\%) and RPC4 (9.9\%) represent the northeastern region and the western region respectively. Observing the spatial patterns of RPCs, it is clearly shown that PC1 corresponds to RPC1, RPC2 and RPC3, while PC2 (figure not shown) solely matches with
RPC4. The temporal scores of these components indicate some years with strong drought episodes with high and frequent fluctuation in inter-annual variability (Figure 4a, b). No strong trend is detected for any of the rotated $\mathrm{PCs}$

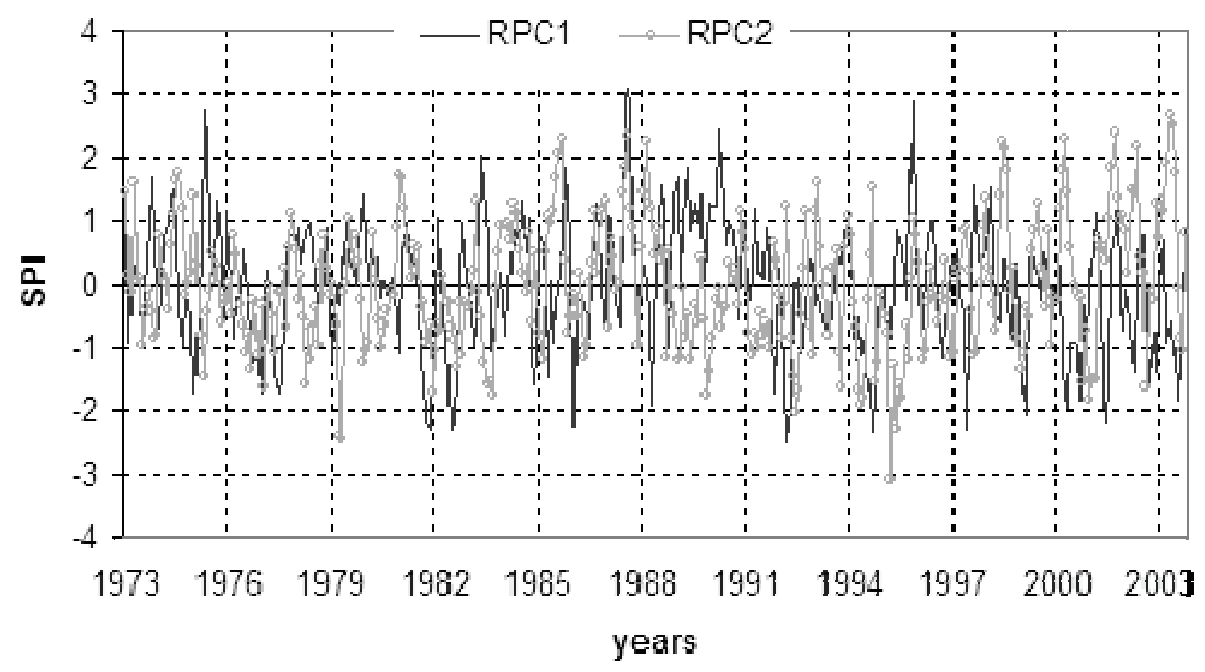

Figure 4: (a) Temporal patterns of correspending RPC-1 and RPC-2 of SPI-3

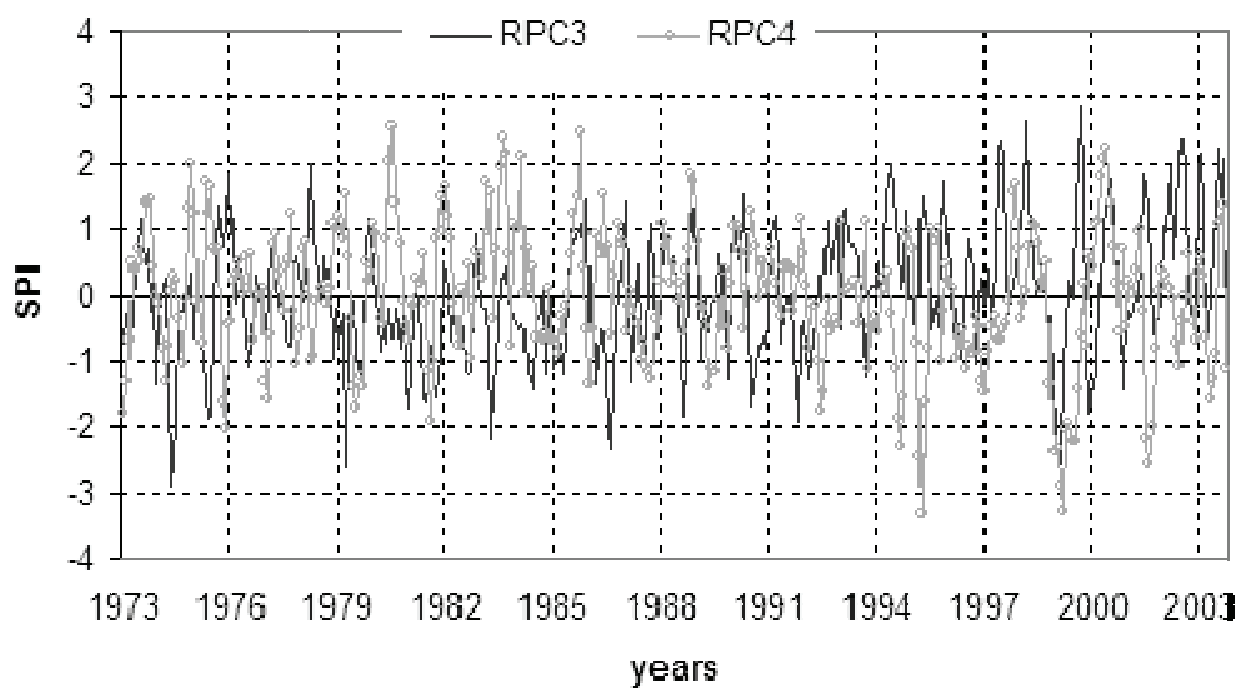

Figure 4: (b) Temporal patterns of correspending RPC-3 and RPC-4 of SPI-3 
For SPI-12, the first mode of unrotated PCA contains 29.1 percent of variance and has nearly homogeneous positive loading with value larger than 0.6 over the central and eastern Nepal (Figure 5a), giving drought conditions with negative time series (Figure 5b). A weak negative loading appears in the northwestern region and fluctuates in the opposite sense to the central and eastern regions. The RPC1 for SPI-12 explains about 16.7 percent of variance and has the higher loading in the eastern region. For this temporal behavior, major dry events are observed in the years 1977,

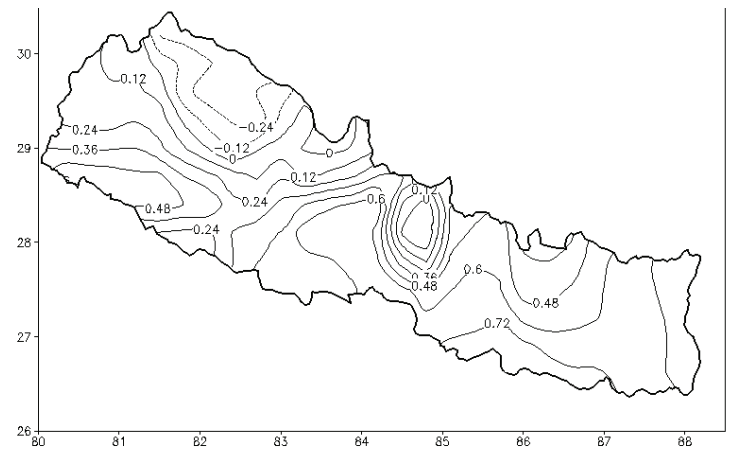

Figure 5: (a) Spatial patterns of unrotated SPI-12/ PC1.

\section{B. RECURRENCE INTERVAL}

The magnitude and duration of dry events were investigated from the series of SPI based on the temporal analysis. When PC/RPC scores show a minimum, we expect negative values also in the SPI time series of the particular region. The frequency of an extreme event is usually expressed by its return period or recurrence interval, which may be defined as average interval of time within which the magnitude of the event reaches or exceeds a certain threshold once (SPI $<-1.0)$.

For the estimation of extreme events, such as drought whose return periods with particular depth and duration have to be known, it is
1982-83, 1992, 1995 and 2001. We have listed the years if the certain month on a year exceeds the lower negative magnitude although most of these events are prolonged for more than a year with strong negative values. The RPC2 is mainly concentrated on the northern and southern parts of 85 to $87 \mathrm{oE}$ and has a variance of 13.1 percent. From the temporal progression, the years 1975, 1982-83, 1992-93 had larger negative values of serious dry conditions. The RPC3 mode mainly represents the central region. The far western region is mainly represented by RPC4.

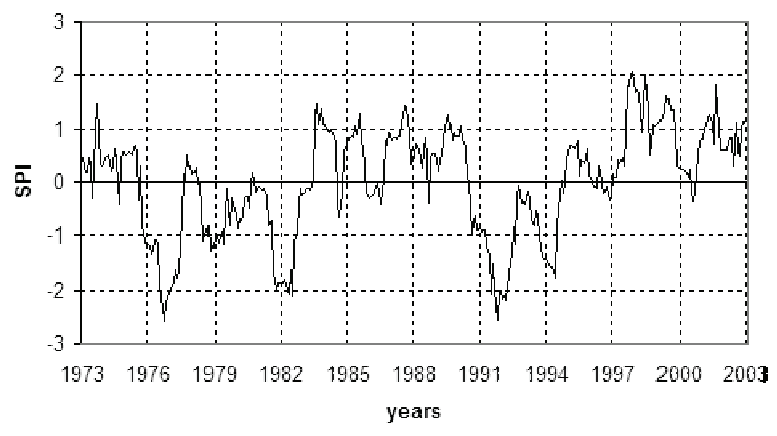

Figure 5: (b) Temporal patterns of unrotated SPI-12/ PC1.

necessary to assume a particular mathematical form of frequency distribution. We estimated the drought magnitude to be the cumulative sum of monthly SPI values smaller than the drought threshold (Table 1); and duration was classified by the number of months in which SPI values remained below this threshold (Vicente-Serrano et al., 2004).

The truncated exponential distribution was used for the drought magnitude, while the geometric distribution was applied to the discrete values of the drought duration. The goodness of fit of these theoretical distributions was examined by quantile-quantile (QQ) plots and KS test. Figure 6a shows QQ plots of the drought magnitudes 
between the truncated exponential distribution and empirical distribution of the RPC1 of SPI-3, while Figure $8 \mathrm{~b}$ shows the QQ plot of the drought duration with geometric distribution, which is generally satisfactory. The upper and lower dashed lines in Figure 6 show the 95\% confidence bands. The QQ plots of the other RPCs are also consistent with this result.

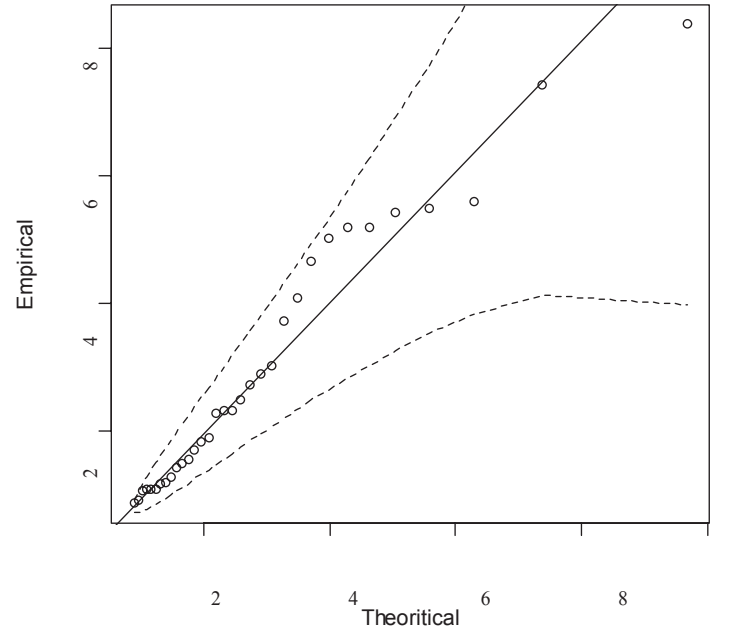

Figure 6: (a) The qunatile-quantile (QQ) plots of the theoretical and empirical distributions for a component of SPI3/RPC for drought magnitude

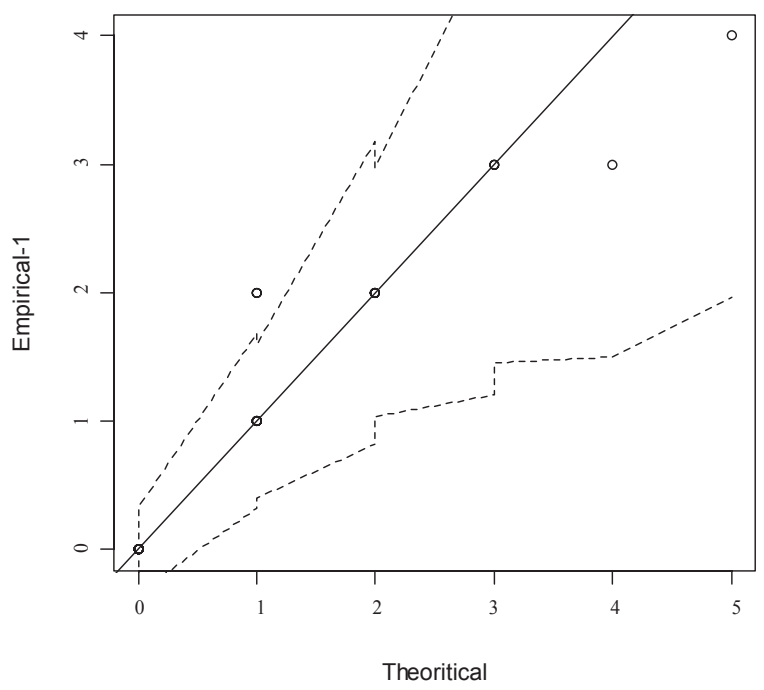

Figure 6: (b) The qunatile-quantile (QQ) plots of the theoretical and empirical distributions for a component of SPI3/RPC drought duration
The return level plot based on respective distribution is shown in Figure 7. For SPI-3 the highest magnitude of dryness is associated with RPC4 (Figure7a), which appears in the western area of Nepal. The region represented by the RPC2, which lies in the southeastern Nepal, has lower probability of long duration of drought (Figure 7b). Within 10-year interval the area under RPC4 has longer duration of dry event compared with the other components. Theoretical and empirical return periods show no statistically significant differences among RPC1, RPC2, RPC3 and RPC4.

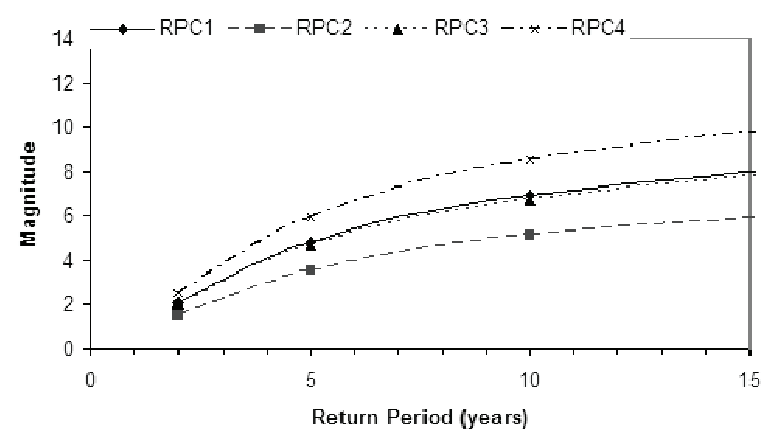

Figure 7: (a) Drought magnitude against return period for SPI-3.

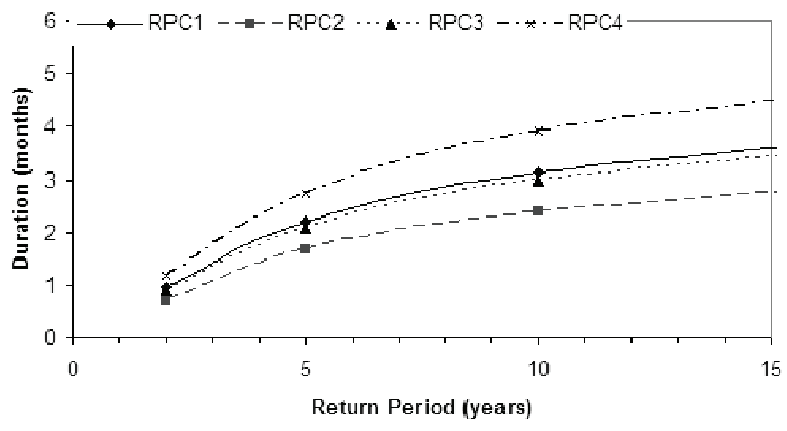

Figure 7: (b) Drought duration against return period for SPI-3. 
For the case of SPI-12, the area defined by RPC2 has the highest magnitude of drought progression. The probability of dryness magnitude for RPC2 is almost double compared with the RPC4 for a 10-year interval (figure not shown). The highest probability of long duration is related to RPC2 and located in the northern and southern part of $85^{\circ} \mathrm{E}$ to $87^{\circ} \mathrm{E}$. We found again no statistical difference among RPCs.

\section{RELATIONSHIP OF SPI WITH CLIMATE INDICES}

Climate indices represent coupled atmosphereocean phenomena giving huge impacts on hydroclimatology around the globe. Therefore, we present the existing relationship of the drought indices over Nepal with SOI and DMI. To understand the inter-annual behavior of drought and possible forcing mechanisms, we use the dominant principal components, SPI-12 (hereafter SPI-12/PC1) and SPI-3 (hereafter SPI-3/PC1) along with SOI and DMI. Spectral analyses were carried out to reveal the dominant oscillations, while Pearson correlation analysis was applied to study the relationship among above mentioned indices. Two tailed student's t-test was used to calculate the significance of the correlation coefficient (CC). Additionally, we tested the autocorrelation of the indices, which supports the student's t-test results.

To expose the dominant oscillation time scale, we applied Multi taper method (MTM) for the above mentioned indices. The MTM analysis used by Ghil et al. (2002) identifies a highly significant peak centered at $\mathrm{f}=0.019$ for SOI. Normally it belongs to 4.5 year/cycle oscillation. Similarly SPI3/PC1 and SPI12/PC1 indicate the peaks at 0.093 and 0.031 respectively. These oscillations are of nearly 1 year/cycle and 2.75 year/cycle. The latter one may be influenced by the ENSO phase since historical record shows ENSO happens at irregular intervals of 2-7 years/cycle (http://www.cpc.noaa.gov).

The CC between SPI-12/PC1 and SOI is 0.46 ( $95 \%$ significant level is 0.11 , Table $2 \mathrm{a}$ ), which is significantly correlated above the 95-percent confidence level. We can notice that some years have very strong negative anomalies of SPI-12/ PC1. Especially the years 1977, 1982-83, 1992-93 and 1995 were extremely dry for SPI-12 observed in Figure 8. We notice the years of 1976-77, 1982, 1991 and 1994 had negative phases of SOI (El Nino). Thus, both SPI-12 and ENSO have phase relationship during these drought years. In contrast, the temporal pattern SPI-3/PC1 is not correlated with either of SOI or DMI (Figure 8, Table 2a)

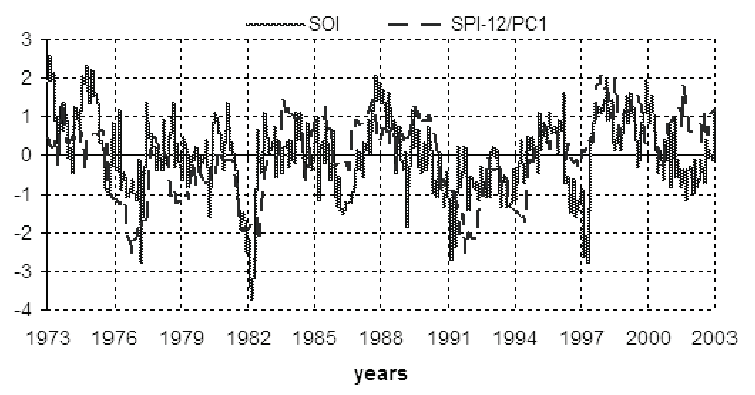

Figure 8: Monthly means of SPI-12/PC1 and SOI

Table 2: Correlations among various SPI and climate indices (a) Monthly indices

\begin{tabular}{|l|c|c|}
\hline & SOI & DMI \\
\hline SPI-12/PC1 & 0.45 & -0.13 \\
\hline SPI-3/PC1 & 0.005 & -0.029 \\
\hline
\end{tabular}

$95 \%$ significant level is \pm 0.11

In addition to SPI over entire Nepal, the correlations were taken between SPI-12 at the individual stations with SOI showing the spatial pattern in Figure 9. It shows that SPI at most of the stations are positively correlated with SOI, although the $\mathrm{CC}$ is not high. The stations lying on 
the central and eastern regions have comparatively strong association with SOI. In case of SPI-3 the association between them is weak (figure not shown)

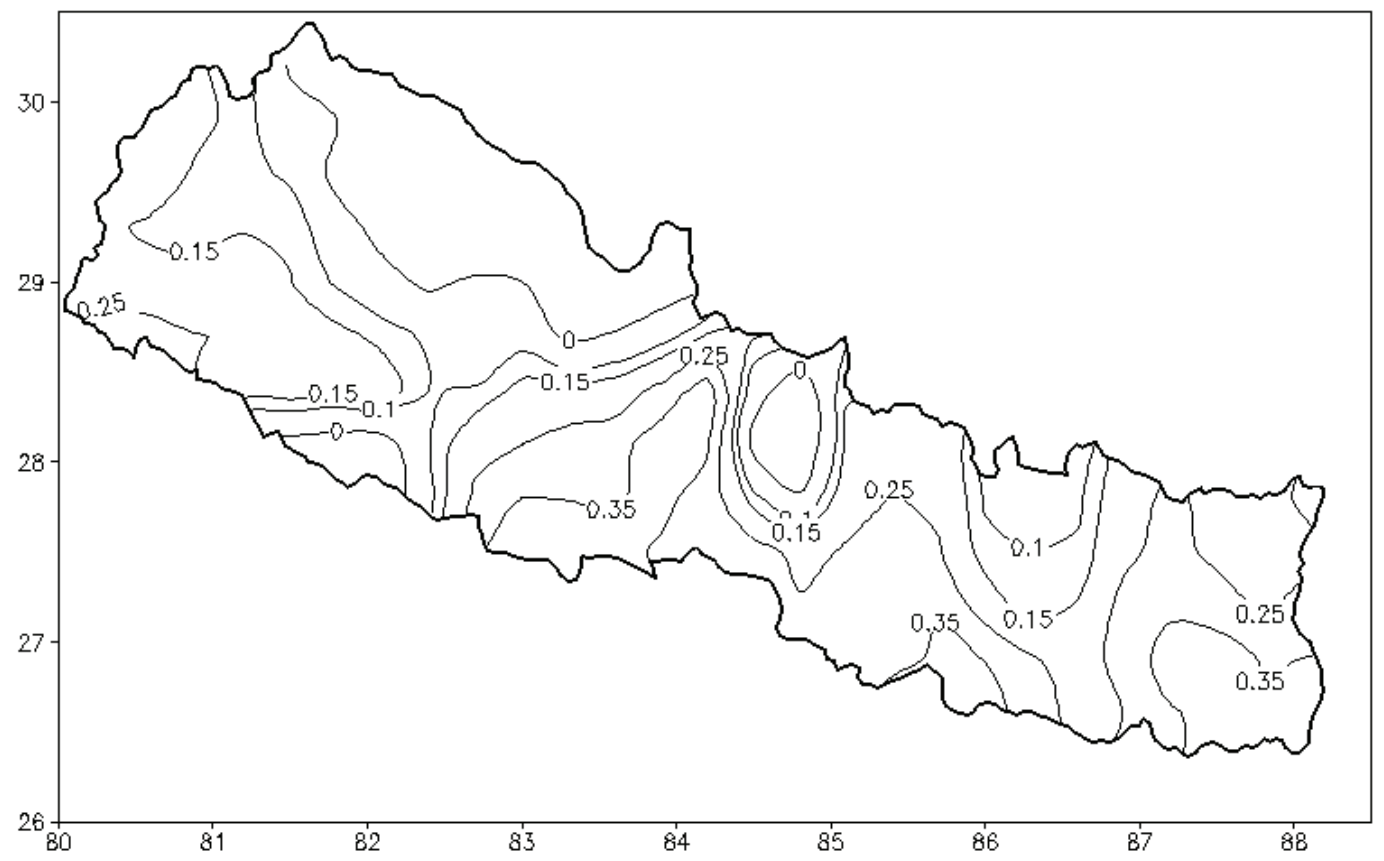

Figure 9: Spatial correlation of SPI-12 at each station with SOI.

Note that 0.11 means significance at a $95 \%$ confidence level.

\section{A. IDENTIFYING THE SUMMER AND WINTER DROUGHT}

Assuming that SPI-3, which is also referred to as the agricultural drought index, may be more suitable for seasonal drought identification, we separated the winter (DJF) and summer (JJA) indices by averaging precipitation data over Nepal and converting them to SPI values for respective years. Out of 31 cases, 6 years were identified to be drought years for winter $(1974,77,85,93,99,2001)$, while only for 4 years $(1977,82,91,92)$ summer drought was detected (Figure.10). Thus, only for one year both winter and summer drought events coincided together. Although the strong drought events hardly occur in both seasons of one year, negative summer SPI-3 followed negative winter SPI-3 in the same years or proceeded to negative winter SPI-3 in the next years: e.g., summer of 1992 and winter of 1993 . This pattern continued until 1994.

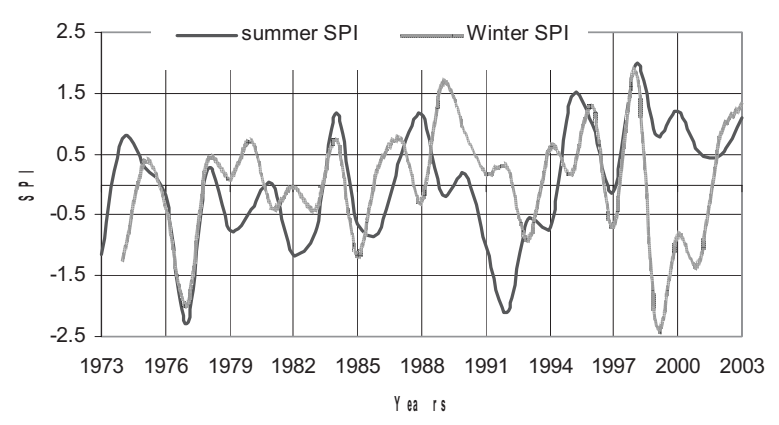

Figure 10: Winter (February) SPI and summer (August) SPI produced from monthly SPI-3 time series. 
No correlation exists between SPI-3 and SOI (Table 2a), although we observed that summer SPI-3 and winter SPI-3 have statistically significant correlations with SOI and DMI respectively. In addition, summer SPI-3 is mostly associated with SPI-12, whereas winter SPI-3 is different (Table 2b). Thus, the overall information implies that summer and winter droughts have different characteristics and origins which are affected by dissimilar hydroclimatology between summer and winter. This suggests that summer drought can be related with ENSO while winter drought can be affected by Indian Ocean DMI. Although only summer drought has received attention, the winter drought can widely and frequently affect Nepal and is equally important for agriculture as well as water resources.

Table 2: Correlations among various SPI and climate indices (b) Annual indices (SOI, SPI and DMI)

\begin{tabular}{|l|l|l|l|}
\hline & \multicolumn{1}{|c|}{ SOI } & \multicolumn{1}{|c|}{ SPI-12 } & \multicolumn{1}{c|}{ DMI } \\
\hline Winter SPI-3 & -0.37 & 0.20 & 0.39 \\
\hline Summer SPI-3 & 0.44 & 0.74 & -0.12 \\
\hline
\end{tabular}

$95 \%$ significant level is \pm 0.35

Further looking into RPCs and DMI linkage, we noticed that winter (Dec.-Feb.) SPI-3/ RPC4 has CC of 0.68 with winter SPI-3 and $\mathrm{CC}$ of 0.33 with winter DMI, which is the highest among CC between SPI-3/RPCs and DMI. This implies that one of the causes for winter drought in western Nepal, which is represented by the fourth component of SPI-3/ RPC, can be linked to DMI, mainly sea surface temperature of western Indian Ocean. Thus, RPCA is capable of extracting the winterdominant component automatically as a useful tool of drought detection.

\section{DISCUSSION AND CONCLUSION}

It is well known that the major factor for drought evolution over Nepal is the lack of precipitation linked with summer monsoon (southeasterly) and wintertime (westerly) circulations. Moreover, large-scale climate phenomena play a crucial role on precipitation system. We used the 3-month and 12-month time scales for monitoring the different drought characteristics from the agricultural and hydrological viewpoints, respectively. The drought occurrence in Nepal over the 33-year period shows some extreme, severe and moderate years in terms of drought intensity. On an average we observed 9, 5 and 5 percentages of area covered by moderate, severe and extreme drought respectively with respect to SPI-12. There are certain variations with respect to time scales and spatial variability in the drought development. The spatial mean SPI series over Nepal is well represented by SPI-12. Droughts are more frequent for SPI-3 and continue longer for SPI-12.

In case of unrotated PCA, drought occurrence appears to be dominated by $\mathrm{PCl}$ on both time scales, which represent droughts for larger surface area in eastern and central Nepal. The more localized patterns based on the varimax rotation show clearly that the country is separated into four sub-regions for potential of drought. The behavior of SPI-3 and SPI-12 is also different in the rotated PCs, which is justified by the spatial representation as well as difference in the recurrence interval of drought magnitude and duration among the rotated PCs. For the SPI3 western and northwestern Nepal has higher probability of drought risk, while central and northeastern Nepal found to be risky under the SPI-12.

Shrestha (2000) and Shrestha et al. (2000) also suggested the relationship of summer rainfall 
over Nepal with SOI. The oscillations among the spectral peaks show that SPI-12/PC1 may have some linkage with ENSO. However, oscillation of SPI-3/PC1 is different. The present study yielded that SOI has statistically significant correlation with SPI-12/PC1 too (Figure 8, Table 2a) but not with SPI-3/PC1. The difference between these two components arises from the fact that the shorter time scale SPI is more sensitive to and represents sub-season accumulation of precipitation. Although the correlations are not extremely high, we found that El Nino is one of the mechanisms of summer drought, while winter SPI-3 could be related with Dipole Mode (Table 2b). In particular, the characteristic of winter SPI-3 is consistent with the suggestion by Saji and Yamagata (2003) that western Indian subcontinent is under influences of the Arabian Sea. The spatial pattern of the correlation between SPI-12 and SOI supports that southeastern Nepal is under the highest risk of drought related with El Nino (Figure 9). The seasonal characters of SPI-3 suggest one-year continuation either from winter to summer or from summer to winter (Figure 10). Further study is necessary to investigate the mechanisms of inducing low precipitation in the western region and consequently winter drought.

In this study, we attempted to relate drought with climate parameters, whereas climatic phenomenon cannot be a solo driver for drought progression. The other factors like local geography, orography, soil parameter and vegetations might be important for drought evolution and severity on a local scale. Therefore, collection of regional environmental information should also be an additional task for understanding, predicting and mitigating drought.

\section{ACKNOWLEDGEMENT}

We show appreciation to the Department of Hydrology\& Meteorology, Government of Nepal for providing the precipitation data. The first author is financially supported by scholarship from Japanese Ministry of Education (MEXT). Climate index data were taken from www.cdc. noaa.gov. We extend our thanks to Dr. Tak Ikeda for his suggestions on statistical functions

\section{REFERENCES}

Abramowitz M, Stegun IA (1965) Handbook of mathematical functions. Dover, 1046 pp

Bonaccorso, B., I Bordi, A. Cancelliere, G. Rossi and A. Sutera, 2003: Spatial variability of drought: An Analysis of the SPI in Sicily, Water Resources. Management, 17, 273296

Bordi, I., K. Fraedrich, F. W. Gerstengarbe, P. C. Werner and A. Sutera, 2004: Potential predictability of dry and wet periods: Silcy and Elbe basin (Germany), Theoretical and Applied Climatology, 77,125-138.

Byun, H. and D. A. Wilhite, 1999: Objective Quantification of Drought Severity and Duration. Journal of Climate, 12, 27472756.

Edward, D. C. and T. B. McKee, 1997: Characteristics of 20th century drought in the United States at multiple time scales. Climatology Report Number 97-2, Colorado State University, Fort Collins, Colorado. 
Ghil M., R. M. Allen, M. D. Dettinger, K. Ide, D. Kondrashov, M. E. Mann, A. Robertson, A. Saunders, Y. Tian, F. Varadi, and P. Yiou, 2002: "Advanced spectral methods for climatic time series," Revision of Geophysics,40(1), pp. 3.1-3.41,

Hayes, M. J., M. D. Svoboda, D. A. Whilhite, O.V. Vanyarkho, 1999: Monitoring 1996 drought using standardized precipitation index. Bulletin of American Meteorological Society, 80, 429-438.

Heim Jr., R. R., 2002: A review of 20th century drought indices used in the United States. Bulletin of American Meteorological Society, 83, 1149-1165.

Komuscu, A. U., 1999: Using the SPI to analyze spatial and temporal patterns of drought in Turkey. Drought network news, 11,713.

Lana, X., C. Serra and A. Burgueno, 2001: Patterns of monthly rainfall shortage and excess in terms of the standardized precipitation index for Catalonia (NE Spain). International Journal of Climatology, 21,1669-1691.

McKee, T. B., N. J. Doesken, J. Kliest, 1993: The relationship of drought frequency and duration to time scales. In Eighth conference on applied climatology, Anaheim, CA, American meteorological Society, Washington DC, p 179-184.
Obasi, GOP, 1994: WMO's role in international decade for natural disaster reduction. Bulletin of American Meteorological Society, 75, 1655-1661.

Patel, N. R., P.Chopra and V.K. Dadhwal, 2007: Analyzing the spatial patterns of meteorological drought using SPI. Meteorological Application, 14,329-337.

Saji, N. H. and T.Yamagata, 2003a: Possible impacts of the Indian Ocean dipole events on global climate, Climate Research, 25, 151-169.

Shrestha, A. B., C. P. Wake, J.E. Dibb, P.A Mayyewski, 2000: Precipitation fluctuation in the Nepal Himalaya and its vicinity and relationship with some large scale climatology parameters. International Journal of Climatology, 20, 317-327.

Shrestha, M. L., 2000: Interannual variation of summer monsoon rainfall over rainfall over Nepal and its relation to southern oscillation Index; Meteorology and Atmospheric Physics, 75, 21-28.

Vicente-Serrano, S. M., J. C. Gonzalez-Hidalgo, M. Luis, J. Raventos, 2004: Drought patterns in the Mediterranean area: the Valencia region (East-Spain). Climate Research, 26, 5-15.

Wilhite, D. A., 2000: Drought as natural hazard: concepts and definitions. In: Whilhite D (eds.) Drought: a global assessment, vol1. Routledge publishers, London, pp 3-18. 